\title{
Enseñar a emprender en universidades de la Región de Coquimbo, Chile: Perfil docente y prácticas de enseñanza
}

Teaching to entrepreneurship in Chilean universities: Teaching profile and teaching practices

\author{
Volumen 20, Número 1 \\ Enero - Abril \\ pp. $1-26$
}

Sebastián Cristóbal Araya-Pizarro

Nibaldo Bernardo Avilés-Pizarro

Citar este documento según modelo APA

Araya-Pizarro, Sebastián Cristóbal y Avilés-Pizarro, Nibaldo Bernardo. (2020). Enseñar a emprender en universidades de la Región de Coquimbo, Chile: Perfil docente y prácticas de enseñanza. Revista Actualidades Investigativas en Educación, 20(1), 1-26. Doi. 10.15517/aie.v20i1.39817 


\title{
Enseñar a emprender en universidades de la Región de Coquimbo, Chile: Perfil docente y prácticas de enseñanza \\ Teaching to entrepreneurship in Chilean universities: Teaching profile and teaching practices
}

\author{
Sebastián Cristóbal Araya-Pizarro ${ }^{1}$ \\ Nibaldo Bernardo Avilés-Pizarro²
}

Resumen: En la actualidad, se encuentra ampliamente documentada la contribución de la educación emprendedora a la actividad empresarial y el desafío que implica su enseñanza de manera efectiva. El siguiente artículo describe el perfil y las prácticas de quienes enseñan emprendimiento en universidades de Chile. El estudio, de diseño metodológico secuencial mixto, incluyó entrevistas a 20 docentes que imparten asignaturas de emprendimiento, junto con la aplicación de una encuesta a 329 estudiantes de 13 carreras de 5 instituciones universitarias de la Región de Coquimbo (Chile), durante el año 2015. Los resultados mostraron que quienes enseñan emprendimiento tienen un perfil homogéneo en cuanto a características personales, académicas y profesionales. Además, tanto el estudiantado como el profesorado prefieren docentes que emprendan, a quienes atribuyen competencias emprendedoras, personales y didácticas superiores (teacherpreneur). Se concluyó que existe una alta valorización del alumnado respecto a las actividades, métodos y herramientas de emprendimiento impartidas, las cuales, en su mayoría, coinciden entre las instituciones y carreras universitarias. Sin embargo, se advierte la necesidad de configurar un currículo más integral, que potencie tanto dimensiones cognitivas como afectivas, en donde la formación entregada posea mayor carácter práctico y vínculo con el ámbito empresarial (networking).

Palabras clave: perfil docente, emprendimiento, educación emprendedora, educación superior.

\begin{abstract}
Currently, the contribution of entrepreneurial education to business activity and the challenge of its effective teaching are widely documented. The following article describes the profile and practices of those who teach entrepreneurship in Chilean universities. The study, of mixed sequential methodological design, included interviews to 20 teachers who teach entrepreneurship subjects, along with the application of a survey to 329 students of 13 careers from 5 university campuses in Region of Coquimbo (Chile), during 2015. The results show that those who teach entrepreneurship have a homogenous profile in terms of personal, academic and professional characteristics. In addition, both students and teachers prefer teachers who undertake, to whom they attribute entrepreneurial, personal and didactic superior skills (teacherpreneur). It's concluded that there is a high appreciation of the students regarding the activities, methods and entrepreneurship tools taught, which mostly coincide between institutions and university careers. However, the need to configure a more integral curriculum that enhances both cognitive and affective dimensions is observed, where the training delivered has a more practical nature and links with the business world (networking).
\end{abstract}

Keywords: teaching profile, entrepreneurship, entrepreneurship education, higher education

\begin{abstract}
${ }^{1}$ Académico-investigador de la Universidad de La Serena, Chile. Doctor@ en Educación, UC de Cuyo, Argentina, Magíster en Liderazgo, Dirección Estratégica y Comunicación, Universidad de La Serena. Dirección electrónica: saraya@userena.Cl Orcid https://orcid.org/0000-0002-5857-8441
\end{abstract}

2 Académico de la Universidad de La Serena, Chile. Doctor Engineering Universidad Tecnológica de Nagaoka, Japón, Master in Business Administration, IEDE, España. Direccion electrónica: naviles@userena.cl Orcid https://orcid.org/0000-0002-1565-7385

Artículo recibido: 29 de junio, 2019

Enviado a corrección: 17 de setiembre, 2019

Aprobado: 14 de octubre, 2019

Los contenidos de este artículo están bajo una licencia Creative Commons 


\section{Introducción}

Durante los últimos años, la educación para emprender se ha convertido en un tema preponderante y de gran interés académico en el mundo (Soria-Barreto, Zuniga-Jara, y RuizCampo, 2016). Se la considera como la responsable de formar personas con competencias emprendedoras estimadas imprescindibles para la adaptabilidad a los nuevos mercados laborales (Sánchez, Ward, Hernández y Florez, 2017) y, por tanto, fuente potencial para el desarrollo y crecimiento económico de la sociedad moderna (Stamboulis y Barlas, 2014). Por ejemplo, el año 2013 la Comisión Europea adoptó el Plan de Acción sobre Emprendimiento 2020, donde propuso tres pilares fundamentales para recuperar el crecimiento económico y el nivel de empleo: educar en emprendimiento, crear un entorno favorable para emprender y dinamizar la cultura emprendedora en Europa (Comisión Europea, 2013).

No obstante, a pesar del reconocimiento del rol de la educación para emprender como elemento de progreso social y territorial, aún existe una visión divergente respecto a cómo llevar a cabo un proceso de enseñanza-aprendizaje efectivo, que garantice el desarrollo íntegro de las competencias emprendedoras del estudiantado (Ahmad, Abu Bakar y Ahmad, 2018; Ismail, Sawang y Zolin, 2018).

En el caso de Chile, desde ya hace algunos años, las autoridades han destacado la necesidad de instaurar un nuevo sistema de educación emprendedora en la nación. Reconocen que enseñar el emprendimiento, además de los beneficios económicos directos que genera por el autoempleo juvenil, ayuda al desarrollo personal del alumnado, que aprende actitudes, habilidades y comportamientos que les permitirán insertarse en el mundo laboral y progresar en sus carreras profesionales (Ministerio de Economía, Fomento y Turismo, 2015). Por consiguiente, los establecimientos chilenos de educación superior han comenzado a reformular sus modelos educativos, potenciando los programas curriculares y planes de estudios de sus carreras con la inclusión de nuevas asignaturas y metodologías de enseñanza enfocadas en el desarrollo de competencias emprendedoras (Catalán, 2016). Todo ello, sin embargo, bajo un marco de desarrollo disímil, caracterizado por el alto grado de heterogeneidad presente en la implementación de los procesos de formación (Herrera y Villalobos, 2018).

En este contexto surge el deseo de analizar el estado de la enseñanza en emprendimiento de las carreras universitarias en Chile, lo que permitirá conocer quiénes llevan a cabo esta tarea, qué conocimientos comparten o transmiten, bajo qué enfoque abordan el emprendimiento (teoría, experiencia o ambas) y qué piensan sus estudiantes 
acerca de la formación que reciben. Específicamente, el estudio plantea como objetivos: primero, caracterizar el perfil de quienes imparten asignaturas de emprendimiento en universidades de la Región de Coquimbo; segundo, describir el enfoque y las metodologías de enseñanza que utilizan en sus programas de clases; y tercero, analizar la percepción del estudiantado en cuanto al proceso formativo que reciben.

La siguiente sección incluye una revisión bibliográfica breve sobre la educación en emprendimiento. Luego, se exponen los antecedentes metodológicos del estudio. Continúa con la presentación de los resultados referidos al perfil docente y las enseñanzas que se practican, mientras que la última parte contiene las conclusiones.

\section{Educación emprendedora}

La educación en emprendimiento se ha transformado en un tema de interés ampliamente abordado, tanto a nivel nacional como internacional, por lo que es posible encontrar diversas investigaciones que analizan el estado del arte de su enseñanza (Čapienè y Ragauskaitè, 2017; Castillo, 1999; Gutiérrez, Asprilla y Gutiérrez, 2016; Herrera y Villalobos, 2018; Sánchez et al., 2017) y su influencia en la intención emprendedora del estudiantado (Barba-Sanchez y Atienza-Sahuquillo, 2017; Díaz-García, Sáez-Martínez y Jiménez-Moreno, 2015; Doğan, 2015; Hattab, 2014; Ismail et al., 2018; Mahendra, Djatmika y Hermawan, 2017; Maresch, Harms, Kailer y Wimmer-Wurm, 2016; Prasetio, 2016; Sondari, 2014; Soria-Barreto, Zúñiga-Jara y Ruiz, 2016).

En general, se admite que la educación formal y la experiencia previa en emprendimiento aumentan la autoconfianza de la persona que va a emprender y afectan su intención emprendedora (Karim, 2016). Por tanto, es posible advertir que cuanto más intensiva sea la enseñanza del emprendimiento en las instituciones de educación terciaria, más probabilidades habrá de que el estudiantado haga el esfuerzo por empezar un nuevo negocio y, de esa manera, contribuir al desarrollo de la economía (Alvarez, DeNoble y Jung, 2006). Como relata Chapa (2008), la educación emprendedora tiene el beneficio de identificar, fomentar y guiar la vocación empresarial, impulsar el autoempleo y relacionar el sector educativo con el sector productivo.

Cabe resaltar, empero, que los resultados sobre la contribución de la educación emprendedora al desarrollo de la intención por emprender son disímiles y no concluyentes. Por ejemplo, Soria-Barreto et al. (2016) mostraron, en un estudio aplicado en jóvenes de una universidad en Chile, que la Intención Emprendedora disminuyó luego de que estos cursaran 
una materia de emprendimiento. Igualmente, en Chile, Poblete y Amorós (2013) concluyeron que contar con educación para el emprendimiento en la universidad no aumentaría la probabilidad de tener intenciones de emprender. Por lo tanto, queda de manifiesto que uno de los principales problemas en el emprendimiento es cómo debe ser enseñado, pues como señalan Ahmad et al. (2018) se sabe muy poco sobre técnicas de enseñanza efectivas para educar en emprendimiento, y hasta ahora sigue siendo un tópico poco desarrollado y con resultados pedagógicos dispares (Ismail et al., 2018)

Respecto a las iniciativas académicas que caracterizan la situación actual de la educación emprendedora en el mundo, destaca el estudio de Sánchez et al. (2017), quienes, luego de revisar 107 fuentes investigativas, evidenciaron, primero, la evolución indiscutible que ha tenido a través del tiempo, pues pasó de ser una simple materia optativa a instituirse hoy como un factor integrado transversalmente en la configuración de los currículos académicos. $\mathrm{Y}$, segundo, el desafío particular de la educación en emprendimiento de convertir en acción las ideas, mediante el uso de estrategias centradas en el aprendizaje experiencial y vivencial, y no en métodos pasivos (como lecturas y exámenes escritos), que se alerta, pueden incluso llegar a reprimir el desarrollo de las actitudes y competencias emprendedoras (Gibb, 2002; Kirby, 2004; Sogunro, 2004).

Tal como propone Castillo (1999): "la enseñanza del emprendimiento, debe fundamentarse en la acción basada en la teoría" (p.13), e impartirse de una manera más objetiva, donde aquellos que tienen la responsabilidad de su formación logren relacionar debidamente la teoría con la práctica (Londoño, 2018). Esto implica, a su vez, un rol docente renovado capaz de generar espacios para la reflexión, la crítica, el trabajo en equipo y la autoformación (Jaramillo, 2008), bajo un modelo centrado en el estudiantado y en el uso de metodologías activas de enseñanza-aprendizaje (Paños, 2017). Al respecto, Arruti (2015) menciona la necesidad de contar con docentes de características emprendedoras (teacherpreneur) que actúen como guías de los procesos de aprendizaje de cada estudiante y no tanto como conferenciantes de clases magistrales.

En cuanto al análisis de las necesidades educativas en la formación emprendedora, Luis, Palmero y Escolar (2015) encontraron que resulta fundamental, por una parte, impartir una enseñanza centrada en cómo gestionar empresas (específicamente con conocimientos sobre marketing, contabilidad y economía) y por otra, brindar conocimientos transversales sobre autoempleo (planes de empresa, negociación y desarrollo de proyectos). En esta línea, hoy es posible advertir la proliferación de diversas herramientas características de los 
programas de estudios en emprendimiento (por ejemplo: Business Model Canvas, Validation Board, Lean Startup, Lean Canvas, Design Thinking, Customer Development Methodology, Elevator Pitch, entre otras), cuyo propósito es la concreción de ideas de negocios.

No obstante, cabe mencionar que la educación de emprendimiento no se reduce o limita a la formación empresarial y/o enseñanza de técnicas y procedimientos para la creación de empresas y su gestión (enfoque utilitarista), sino que persigue la formación integral de sujetos sociales capaces de emprender en todos los ámbitos de actividad sociocultural y profesional. Tal como indica Vásquez (2017): "es prioritario educar un ser emprendedor vinculado a los procesos cognitivos y volitivos del emprendimiento" (p. 144).

De este modo, la docencia universitaria debe ser capaz de garantizar el desarrollo cognitivo, actitudinal y valórico del alumnado, con base en la implantación de enfoques, estrategias pedagógicas y estilos de enseñanza que potencien la participación activa del estudiantado en la construcción y desarrollo de su propio aprendizaje (Aldana-Rivera, TafurCastillo, Gil y Mejía, 2019). Al respecto, Castro, Renés y León (2014) identificaron una serie de desafíos para la incorporación del emprendimiento en el sistema educacional en Europa. Destacaron, por ejemplo, el deber de repensar la forma de enseñanza para estimular las aptitudes emprendedoras del alumnado, junto con disponer de un profesorado idóneo que opere bajo un enfoque social más amplio que el mero economicista.

La Región de Coquimbo, por su parte, posee la cuarta conurbación urbana más grande de Chile. De acuerdo con el Global Entrepreneurship Monitor (Mandakovic y Serey, 2017), la zona presentó el segundo mayor porcentaje de emprendedores con altas expectativas de crecimiento en empleo (32\%) y exhibe indicadores de emprendimiento similares a los observados en países basados en innovación (Soria y Honores, 2016). Estas características proveen a la Región de un potencial básico para el desarrollo de la innovación y el emprendimiento, que la educación emprendedora podría impulsar de manera eficiente y competitiva.

Por último, cabe indicar que, en Chile, las universidades se caracterizan por poseer distintos grados de logro en la implementación de sus procesos formativos en emprendimiento, en el que se evidencia una gran disparidad en su ejecución y sus resultados (Herrera y Villalobos, 2018). 


\section{Metodología}

\subsection{Enfoque}

En el estudio realizado se utilizó un diseño metodológico secuencial mixto, de tipo descriptivo y corte transeccional, que combinó técnicas de recolección de información cualitativa y cuantitativa, con el propósito de contar con resultados generalizables para la situación regional de la enseñanza en emprendimiento. Dada la escasa información existente, se optó por iniciar el diseño con una fase cualitativa que sirvió como insumo para la etapa cuantitativa. Ello permitió la triangulación metodológica secuencial entre las entrevistas realizadas al profesorado y la encuesta aplicada a estudiantes, además de su contraste con literatura y hallazgos de otras investigaciones afines.

\subsection{Unidades de análisis}

Para la identificación de las unidades de estudio, se revisaron las mallas curriculares de las carreras que impartían emprendimiento (9) en todas las universidades de la Región de Coquimbo, durante el año 2015 y se lograron identificar aquellas que contaban con asignaturas obligatorias (13), electivos de formación profesional o talleres de desarrollo personal (5) en el área de emprendimiento e innovación. Dicha información, así como los contactos con docentes y estudiantes, se obtuvo directamente desde las direcciones, jefaturas y secretarías de Escuela de cada institución.

El tamaño de la muestra estudiantil ( $n=329)$ se computó sobre una población de 520 jóvenes que cursaban materias de emprendimiento y/o innovación, utilizando un nivel de confianza del $95 \%$, un margen de error de $3,28 \%$ y una proporción del $50 \%$. Las personas participantes de cada universidad fueron seleccionadas a través de un muestreo probabilístico aleatorio simple, bajo la distribución siguiente: U. Católica del Norte $(44,3 \%), \mathrm{U}$. de La Serena (18,6\%), U. Tecnológica de Chile INACAP $(17,1 \%)$, U. Santo Tomás $(15,6 \%)$ y U. Pedro de Valdivia $(4,5 \%)$.

La muestra del profesorado, por otro lado, se compuso de 20 docentes que durante el periodo de estudio contaban con cursos de emprendimiento vigentes y cuya escogencia se realizó mediante un muestreo no probabilístico de tipo intencional. (Véase la Tabla 1). 
Tabla 1: Asignaturas de los planes de las carreras seleccionadas relacionadas con el emprendimiento e innovación, Coquimbo, Chile, 2015

\begin{tabular}{|c|c|c|c|}
\hline Ues & Carreras & Asignaturas & Tipo \\
\hline \multirow[t]{7}{*}{ ULS } & Ing. en Adm. de empresas & Emprendimiento & OBL \\
\hline & Ing. en Adm. de empresas & Emprendimiento e Innovación Social & OBL \\
\hline & Ing. Comercial & Comercialización & OBL \\
\hline & Ing. Civil & Taller de Innovación y Emprendimiento & EFP \\
\hline & Periodismo & Emprendimientos Periodísticos & EFP \\
\hline & Lic. en Química & Gestión de la Innovación & $\mathrm{OBL}$ \\
\hline & Diseño gráfico & Gestión del Diseño & $\mathrm{OBL}$ \\
\hline \multirow[t]{4}{*}{ UCN } & Ing. Comercial & Desarrollo de Actitud Emprendedora & OBL \\
\hline & Ing. Comercial & Identificación de Oportunidades de Negocios & OBL \\
\hline & Ing. en Acuicultura & Emprendimiento e Incubación de Negocios & OBL \\
\hline & Nutrición y Dietética & Administración de Servicios de Alimentación I & $\mathrm{OBL}$ \\
\hline \multirow[t]{3}{*}{ UST } & Ing. Comercial & Creación de Empresas & $\mathrm{OBL}$ \\
\hline & Ing. Comercial & Liderazgo y Emprendimiento & TDP \\
\hline & Ing. Comercial & Innovación & EFP \\
\hline \multirow[t]{2}{*}{ INACAP } & Ing. en Administración & Emprendimiento & OBL \\
\hline & Ing. en Construcción & Intraemprendimiento & OBL \\
\hline \multirow[t]{2}{*}{ UPV } & Ing. Comercial & Creación de Empresas (Bienes) & OBL \\
\hline & Ing. Comercial & Método Lean & EFP \\
\hline
\end{tabular}

Nota: OBL=Obligatorio; EFP=Electivo de Formación Profesional; TDP=Taller de Desarrollo Personal

Fuente: Elaboración propia, 2018

\subsection{Técnicas de recolección}

Las técnicas utilizadas para la recolección de datos fueron la entrevista y la encuesta. La entrevista semi-estructurada aplicada a docentes fue presencial, de carácter anónima y contó con el compromiso de confidencialidad. Se compuso de 8 preguntas abiertas y abarcó 3 tópicos principales: características del profesorado que enseña emprendimiento, metodologías de enseñanza y percepción sobre el emprendimiento y su formación. Además, se agregaron 6 preguntas de caracterización (sexo, edad, profesión, universidades en que trabaja, asignaturas que imparte y experiencia docente). Las respuestas fueron grabadas y registradas digitalmente, previa autorización de quienes participaron. Los relatos de cada docente fueron identificados con la notación correlativa siguiente: ENTREVISTA1, ENTREVISTA2, ENTREVISTA3, etcétera. Con la finalidad de garantizar la autenticidad de los hallazgos de la investigación, se efectuó una transcripción textual de los relatos, los cuales fueron posteriormente contrastados con los resultados obtenidos del estudiantado y de la revisión de la literatura referida al tema.

El cuestionario aplicado a estudiantes, por su parte, fue personal, sincrónica, de carácter anónimo y confidencial. Incluyó 8 preguntas (7 cerradas y 1 abierta) donde se 
abordaron las temáticas siguientes: concepción del término emprendedor, actividades y metodologías de emprendimiento conocidas, el aporte percibido de las asignaturas cursadas y de las actividades desarrolladas, el grado de satisfacción respecto de los contenidos vistos en clases, opinión respecto del perfil docente idóneo para su enseñanza y sugerencias para potenciar las asignaturas de emprendimiento.

El cuestionario fue validado por dos expertos en la materia, experimentados en el campo del emprendimiento e innovación. Además, se aplicó un cuestionario piloto a estudiantes con el perfil investigativo, cuyos resultados permitieron ajustar el instrumento previo a su aplicación final.

\subsection{Procesamiento de análisis}

El análisis cualitativo de datos incluyó el análisis de contenido (categórico descriptivo) por medio de la codificación y categorización de las entrevistas. Las categorías se construyeron desde una perspectiva inductiva, mediante la definición de categorías centrales obtenidas a partir de la reducción sistemática de las unidades temáticas que surgieron de la interpretación de los propios relatos del profesorado, sin contemplar categorías analíticas predefinidas teóricamente. Luego, estas fueron examinadas bajo un análisis estadístico de datos textuales (conteo de ocurrencia de palabras) y presentadas en tablas de frecuencias y mapas mentales que sintetizaron los principales constructos bajo estudio. Entre las técnicas utilizadas para el análisis cuantitativo de los datos del cuestionario se cuentan: la construcción de tablas de frecuencias, el cómputo de estadísticos descriptivos básicos y la prueba de asociación no paramétrica chi-cuadrado, donde se usó un nivel de significancia del 5\%. En específico, se buscó confirmar las asociaciones entre: (i) la concepción del término emprendedor y el área de desempeño de la profesión, (ii) la concepción del término emprendedor y la universidad, (iii) la satisfacción con las herramientas de emprendimiento y el área de desempeño profesional y (iv) la satisfacción con las herramientas de emprendimiento y la universidad.

Por último, cabe destacar que la información recolectada fue procesada a través del software estadístico SPSS, versión 24 para MS Windows. 


\section{Resultados}

\subsection{Perfil del profesorado que enseña emprendimiento}

Los resultados del análisis de las preguntas de caracterización de las entrevistas revelaron que la mayoría del profesorado que enseña emprendimiento en la Región son hombres (80\%), tienen entre 31 y 50 años de edad $(60 \%)$, son profesionales de la ingeniería comercial $(35 \%)$ e ingeniería civil industrial $(25 \%)$. Además, se desempeñan mayormente en la U. de La Serena (48\%) y la U. Católica del Norte $(20 \%)$ y poseen en promedio 10 años de experiencia académica (55\%). Ver la Tabla 2.

Tabla 2: Características del profesorado que enseña emprendimiento, Coquimbo, Chile, 2015 $(n=20)$. Valores en Porcentaje (\%)

\begin{tabular}{|c|c|c|}
\hline Variable & Categoría & Porcentaje \\
\hline \multirow[t]{2}{*}{ Sexo } & Masculino & 80 \\
\hline & Femenino & 20 \\
\hline \multirow[t]{4}{*}{ Edad } & Menos de 31 años & 5 \\
\hline & Entre 31 y 40 años & 60 \\
\hline & Entre 41 y 50 años & 25 \\
\hline & Más de 50 años & 10 \\
\hline \multirow{10}{*}{$\begin{array}{l}\text { Profesión } \\
\text { (Carrera) }\end{array}$} & Ingeniería Comercial & 35 \\
\hline & Ingeniería Civil Industrial & 25 \\
\hline & Diseño Gráfico & 5 \\
\hline & Periodismo & 5 \\
\hline & Nutrición & 5 \\
\hline & Administración Turística & 5 \\
\hline & Ingeniería en Alimentos & 5 \\
\hline & Ingeniería en Control de Gestión & 5 \\
\hline & Psicología & 5 \\
\hline & Enfermería & 5 \\
\hline \multirow{5}{*}{$\begin{array}{l}\text { Universidades en que } \\
\text { trabajan }\end{array}$} & U. de La Serena & 48 \\
\hline & U. Católica del Norte & 20 \\
\hline & U. Santo Tomás & 17 \\
\hline & U. Tecnológica de Chile Inacap & 10 \\
\hline & U. Pedro de Valdivia & 5 \\
\hline \multirow[t]{3}{*}{ Experiencia docente } & Menos de 11 años & 55 \\
\hline & Entre 11 y 20 años & 40 \\
\hline & Más de 20 años & 5 \\
\hline
\end{tabular}

Fuente: Elaboración propia, 2018

Respecto al tipo de vinculación con el emprendimiento, se puede mencionar que la mayoría de los responsables de su enseñanza, han emprendido al menos una vez en su vida (85\%), principalmente en áreas de apoyo a la gestión de empresas, como las consultorías y 
las capacitaciones dirigidas a las pequeñas y medianas empresas locales. Actualmente, un grupo importante del profesorado (75\%) tiene emprendimientos en funcionamiento, con rentabilidad estable, y otros en etapas tempranas de desarrollo y crecimiento, tal como lo reflejan los siguientes tres testimonios: (i) ENTREVISTA19: "Lo que hacemos nosotros son asesorías tanto contables como de implementación de control de gestión en empresas de diferentes tipos y niveles. Llevamos alrededor de 4 años funcionando y por el momento nos está generando buenos resultados"; (ii) ENTREVISTA15: "Estoy haciendo asesorías, estas asesorías las hago todas bajo forma legal y establecida, entregamos boletas o facturas dependiendo del caso, por lo que ese se podría decir que es mi emprendimiento actual"; y (iii) ENTREVISTA12: "A partir del 2012 me dedique a la consultoría de negocios que es mi emprendimiento personal, que hasta el día de hoy me ha dado estabilidad financiera".

En relación con el perfil académico del profesorado, se constató que aun cuando casi la totalidad de este posee algún postgrado o tipo de perfeccionamiento complementario a su título profesional (90\% tiene grado de magíster), solo la mitad posee alguno específico en el área de emprendimiento e innovación. Por otro lado, la mayoría declaró no haber trabajado directamente en instituciones públicas ligadas al fomento del emprendimiento, sino solo como apoyo externo en asesorías y/o evaluaciones solicitadas. Y quienes lo han hecho, se han desempeñado en instituciones públicas como: Corporación de Fomento de la Producción (CORFO), Servicio de Cooperación Técnica (SERCOTEC) y Fondo de Solidaridad e Inversión Social (FOSIS), entre otras.

En promedio, el profesorado lleva seis años dictando asignaturas vinculadas al emprendimiento con una cantidad media de tres materias impartidas durante su carrera docente. También, cabe notar, que casi la totalidad de quienes fueron entrevistados considera que sí es necesario haber emprendido para enseñar a otros a emprender (90\%), ya que transmitir la experiencia propia es algo que perciben como más valorizado por el estudiantado, y a su vez se sienten más capaces de enriquecer mejor las clases, tal como lo evidencian los relatos siguientes: (i) ENTREVISTA1: "Creo que eso es crucial, yo creo en los referentes y de predicar con el ejemplo. La teoría sin praxis no es nada, yo creo que es súper necesario haber emprendido para enseñar emprendimiento"; (ii) ENTREVISTA5: "Creo que el haber emprendido ayuda mucho más a entender el proceso del valor de emprender [...] creo que luego de haber emprendido ahora soy capaz de hacer mejores clases de innovación y emprendimiento que si no lo hubiera hecho"; y (iii) ENTREVISTA19: "Creo que es necesario haber emprendido, más por el tema de ejemplificar realmente lo que significa 
emprender [...] el emprendimiento es más bien práctico, entonces si se puede enseñar de la experiencia mejor".

Similar respuesta se obtuvo del alumnado, el 76\% manifestó que sí es necesario haber emprendido para enseñar a emprender (41\%, muy de acuerdo; 35\%, de acuerdo; $13 \%$, indiferente; $9 \%$, desacuerdo y $2 \%$, muy en desacuerdo), lo que confirma una percepción generalizada de la contribución positiva de la experiencia al perfil docente de quien enseña emprendimiento, empero menos marcada que el profesorado. La Figura 1, contrasta las respuestas del estudiantado con las respuestas obtenidas del análisis estadístico de los datos textuales de las entrevistas a docentes.

Figura 1: Porcentaje de estudiantes y docentes que perciben necesario haber emprendido para enseñar emprendimiento, Coquimbo, Chile, 2015
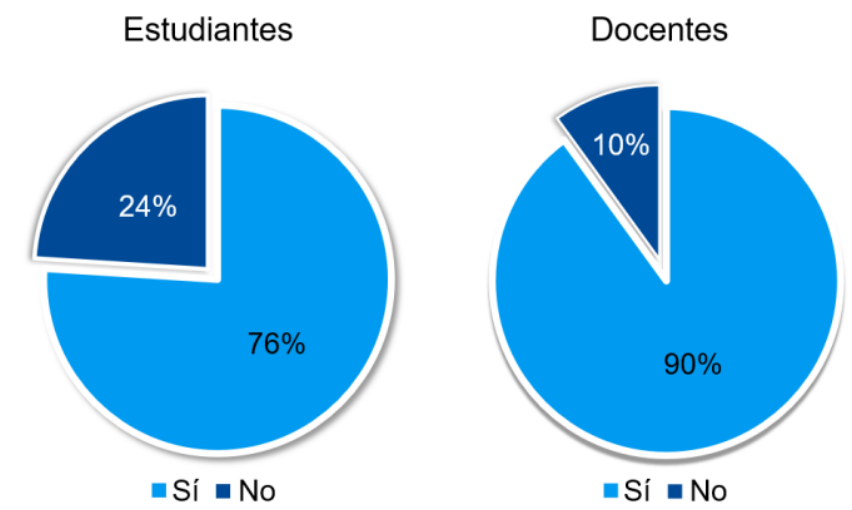

Fuente: Elaboración propia, 2018

Lo anterior encuentra coincidencia con la figura del teacherpreneur propuesta por Arruti (2015), quien advierte la necesidad de contar con docentes que compartan las mismas características y valores de una persona emprendedora, tanto personales (creatividad, autonomía, confianza en uno mismo, tenacidad, sentido de la responsabilidad y capacidad para asumir riesgos) como sociales (liderazgo, espíritu de equipo y solidaridad). Esto implica que quien enseña emprendimiento, aun cuando posea una empresa propia, necesita de una formación particular en competencias (emprendedoras) que refleje, en su actuación en el aula, un modelo de persona emprendedora, lo que supone, por cierto, adoptar una serie de metodologías de enseñanza y evaluación afines. 


\subsection{Metodologías y herramientas utilizadas en la enseñanza de emprendimiento}

El profesorado destacó utilizar en la enseñanza de emprendimiento, métodos innovadores, activos o basados en la acción (Samwel, 2010), donde incluyen varias herramientas y metodologías reconocidas internacionalmente, tales como el lienzo Business Model Canvas, el Método Lean Start-up y los tradicionales Planes de Negocios, tal como se aprecia en el relato de ENTREVISTA10: "Incluyo el Lean Start-up, modelos de negocios basados en el modelo Canvas, vemos casos de éxitos, casos de fracasos, Elevator Pitch, prototipos, aceleración de negocios y fuentes de financiamiento"; o de ENTREVISTA15: "Hay un tema de generación de ideas, creatividad [...] formulación de los nuevos modelos de negocios, innovación en los modelos de negocio [...] colaboración para el emprendimiento [...] también vemos el plan de negocios que es lo más típico".

A su vez, también indicaron que se insta la ideación y creación de proyectos de emprendimientos ficticios, que son presentados por estudiantes al final del curso, tal como se revela en la ENTREVISTA12: "se insta al alumno a un proceso de reflexión, todo esto acompañado de metodologías y herramientas como el Design Thinking, Customer Development, y finalmente se pasa al proceso de ideación e implementación del proyecto".

Estos testimonios coinciden con lo señalado en la encuesta de estudiantes, quienes reconocieron como herramientas de emprendimiento más frecuentes: el Business Model Canvas (269 menciones), el Plan de Negocios (250 menciones), el Método Lean Start-Up (219 menciones), el Mapa de Empatía (193 menciones), entre otros. Véase la Figura 2.

\section{Figura 2: Número de menciones de las herramientas de emprendimiento más reconocidas por} el estudiantado, Coquimbo, Chile, $2015(n=329)$

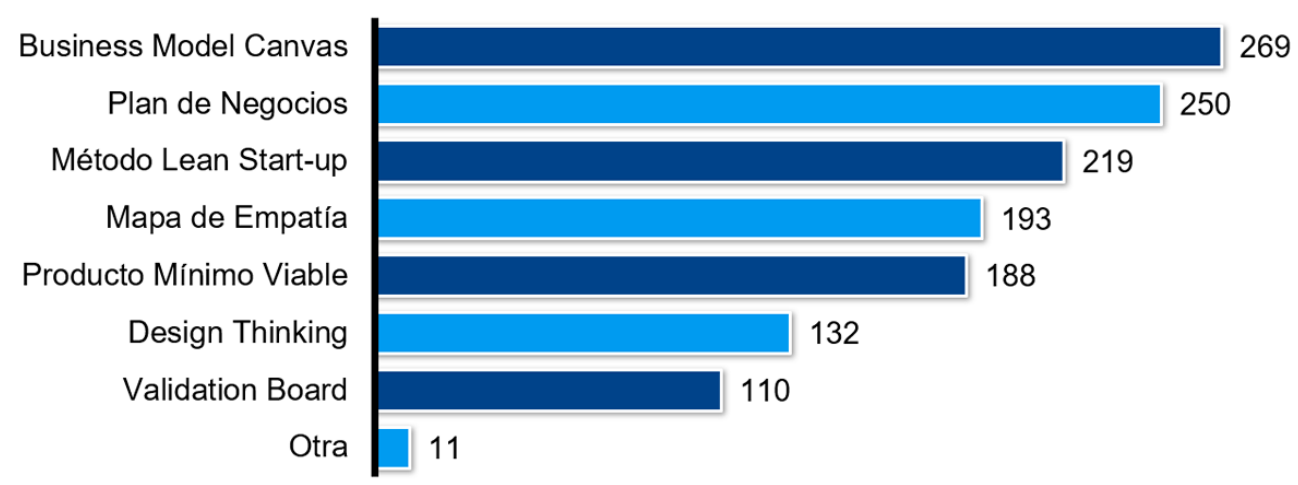

Fuente: Elaboración propia, 2018 
El estudio reciente desarrollado por Paños (2017), sobre metodologías activas para el fomento de la educación emprendedora, sintetiza once técnicas apropiadas para estimular la competencia emprendedora según varios referentes internacionales (estudio de casos, juegos de negocios empresariales y simulaciones, learning by doing, aprendizaje experiencial, charlas con emprendedores, design-based Learning, creación planes de negocios, aprendizaje por proyectos, aprendizaje basado en problemas, aprendizaje cooperativo y aprendizaje-servicio). Sus hallazgos permiten evidenciar que aun cuando el profesorado chileno (Región de Coquimbo) utiliza varios de los métodos allí mencionados, estos se aplican mayormente bajo un contexto de simulación (situaciones ficticias dentro del aula de clases), sin potenciar el uso de técnicas que involucren situaciones reales, o que incluyan trabajo en terreno o impliquen la participación activa de organizaciones privadas, públicas y actores relevantes del ecosistema emprendedor local, nacional e internacional.

El examen de las distintas metodologías conocidas por estudiantes, según la asignatura cursada, permitió identificar aquellas áreas de estudio (ciencias sociales, tecnología, arte y diseño, ciencias exactas y naturales, salud y agropecuaria) que utilizan una mayor variedad de técnicas. Destacan, en orden descendente, las áreas de las Ciencias sociales (particularmente las ciencias administrativas), Arte y diseño, Tecnología, Ciencias exactas y naturales, Agropecuaria y, finalmente, Salud (Véase la Figura 3).

Figura 3: Porcentaje de estudiantes por áreas de estudio según herramientas de emprendimiento, Coquimbo, Chile, 2015

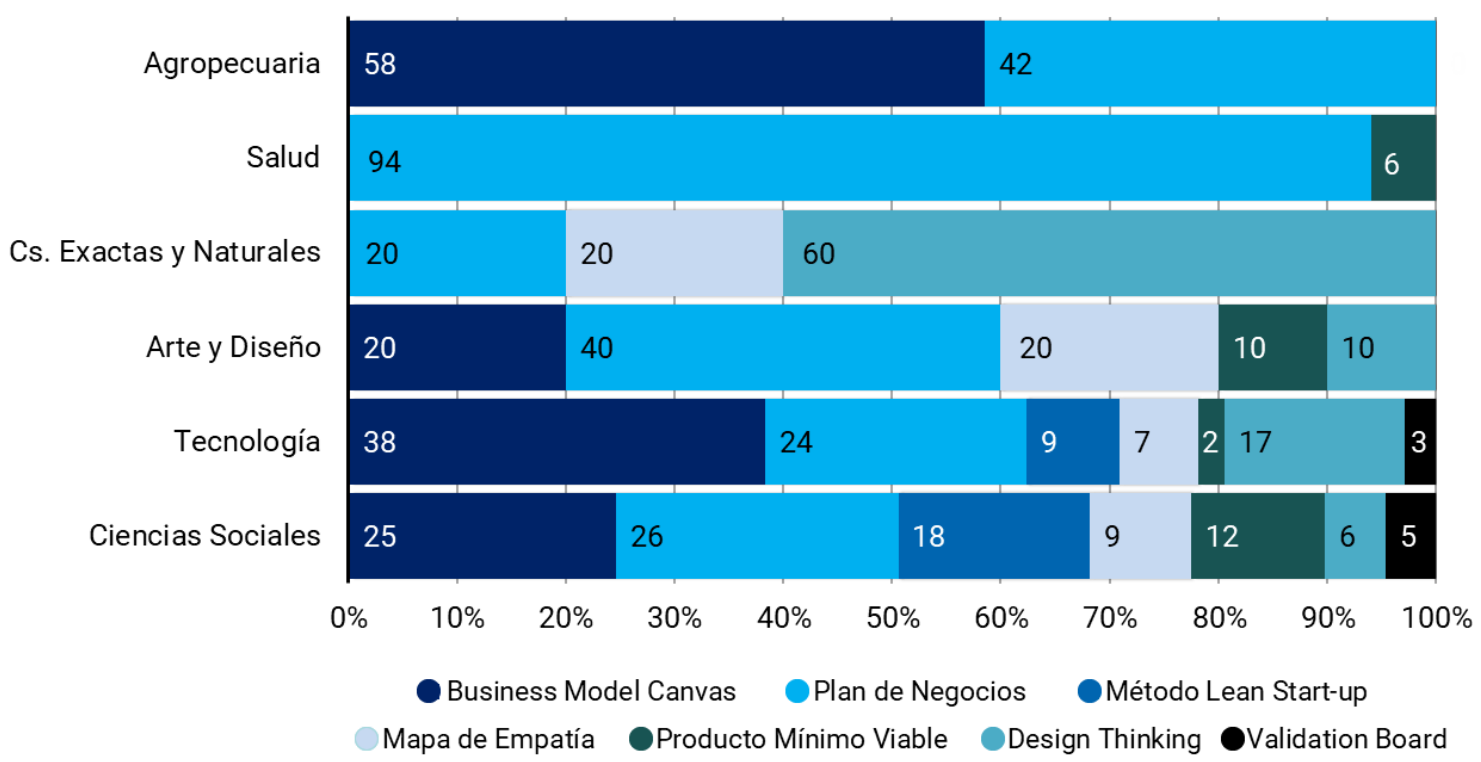

Fuente: Elaboración propia (2018) 
Dentro de las carreras que aplican mayor número de herramientas se encuentran: Ingeniería en administración de empresas, Ingeniería comercial y Diseño gráfico, en concordancia con lo declarado en sus perfiles de egreso. Mientras que las carreras que obtuvieron un menor ranking se limitaron a la enseñanza de planes de negocios y Business Model Canvas.

Por otro lado, ante la consulta sobre qué se busca transmitir en clases, el profesorado indicó, además de los conocimientos teóricos propios de la materia, cuatro tópicos relevantes: (1) la importancia de desarrollar habilidades emprendedoras como: el liderazgo, trabajo en equipo, comunicación efectiva, creatividad, iniciativa, entre otras; (2) socialización de historias de emprendimiento (éxito y fracaso), donde se entremezclan vivencias personales y la revisión de casos tanto nacionales como internacionales; (3) reflexión sobre los valores éticos que deben regir el obrar de quien emprende, tales como la honestidad, la responsabilidad social, el respeto y la transparencia y, (4) ilustración de consejos para emprender adecuadamente, sobre todo relacionados con las redes de apoyo existentes, la disciplina, el autoconocimiento y la autogestión del emprendedor o emprendedora (Véase la Figura 4).

Figura 4: Temáticas que busca transmitir el profesorado que enseña emprendimiento, Coquimbo, Chile, 2015

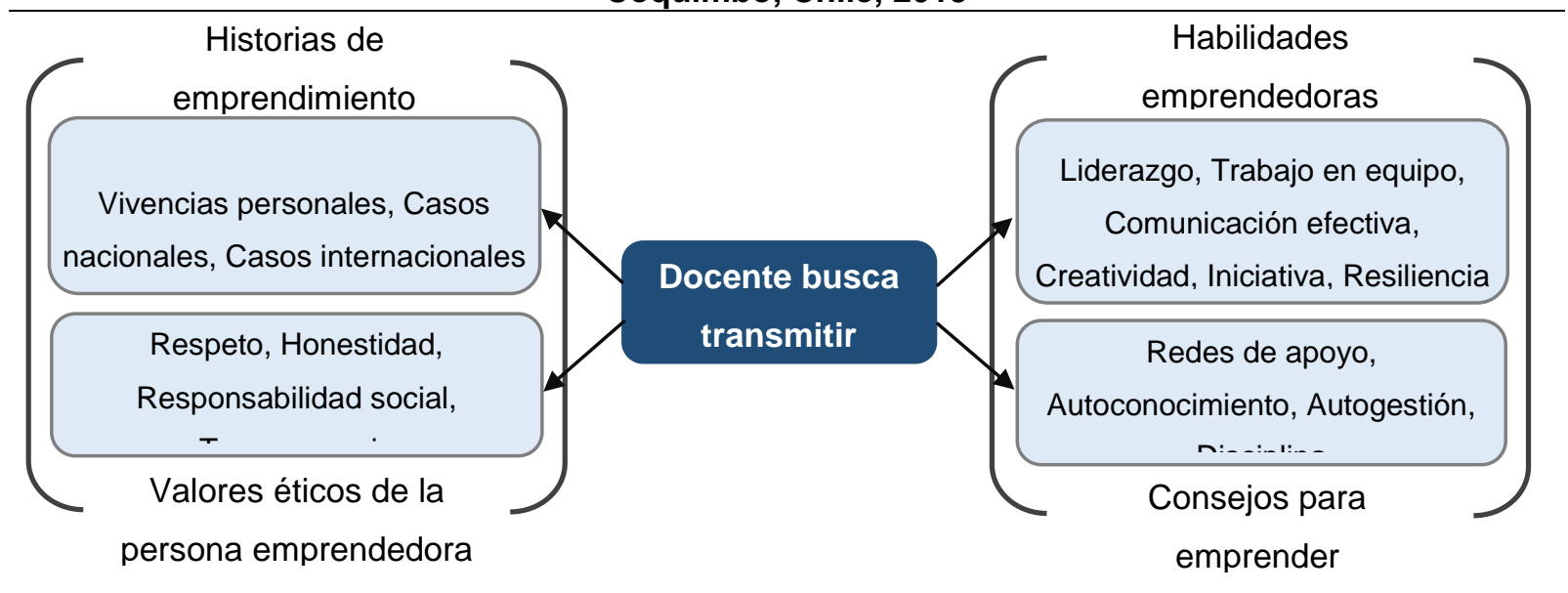

Fuente: Elaboración propia, 2018

Del análisis previo, y de acuerdo a la clasificación de educación emprendedora señalada por Sánchez et al. (2017), se deriva que en las universidades de la Región de Coquimbo estarían desarrollándose dos tipologías: educar sobre emprendimiento y educar para emprender. Es decir, se imparte conocimiento general sobre los conceptos relacionados 
con el emprendimiento (educar sobre emprendimiento) y también se realiza un acercamiento teórico y práctico para proveer conocimiento y habilidades emprendedoras (educar para emprender). Sin embargo, el aprendizaje no se fundamenta en un proceso experimental (Action-based) en el que el alumnado aprenda directamente por medio de experiencias emprendedoras (educar a través de emprendimiento).

Por tanto, se aprecia que las instituciones locales exhiben un papel educativo tradicional en el campo investigativo y docente, todavía lejano del perfil de las denominadas universidades emprendedoras, cuyo accionar se centra en la comercialización de nuevos conocimientos con base en la tecnología (generación, adopción y transferencia), la adaptación constante a las demandas imperantes de la sociedad y la colaboración activa de las esferas institucionales académicas, industriales y gubernamentales (Ahmad, Halim, Ramayah, Popa y Papa, 2018; González-García, Becerril y Fonseca, 2018).

\subsection{Percepción del estudiantado respecto de la enseñanza del emprendimiento}

\subsubsection{Concepto de emprendedor}

Para al alumnado, la proposición que mejor representa el concepto de emprendedor corresponde a Ser una persona innovadora (44\%), seguido de Iniciar un negocio (36\%) y, por último, Estilo de vida (20\%). Esto muestra coincidencia con el tradicional enfoque del emprendedor-innovador propuesto por Schumpeter (Marulanda, Montoya y Vélez, 2014) y con la propia evolución del término Persona Emprendedora, que se vincula a quien vive en un estado de innovación permanente (Rodríguez, 2009).

La aplicación de la prueba de independencia chi-cuadrado reveló que existe una asociación estadísticamente significativa entre el área de desempeño de la profesión (ingeniería, ciencias exactas y salud y ciencias sociales) y la concepción del término emprendedor (iniciar un negocio, estilo de vida y ser innovador), $x 2(4, N=329)=16.98$, $\mathrm{p}<$.01. En particular, si bien las tres áreas profesionales se inclinaron por la frase Ser una persona innovadora, en Ingeniería existe una preferencia más marcada (49\%) que en las Ciencias exactas y salud (45\%) y las Ciencias sociales (43\%). En sentido opuesto, Ingeniería muestra una menor valoración por el concepto Iniciar un negocio (27\%) que las áreas de las Ciencias exactas y salud (39\%) y las Ciencias sociales (37\%).

De igual modo se halló, mediante la prueba chi-cuadrado, una asociación relevante entre la noción del término emprendedor y la institución universitaria (U. de La Serena, U. 
Católica del Norte, U. Santo Tomás, U. Tecnológica de Chile Inacap y U. Pedro de Valdivia), X2 $(8, N=329)=28.60, p<.01$. Puntualmente, se denota que la U. Pedro de Valdivia $(63 \%)$ y la U. Santo Tomás (58\%), tienen mayor predilección por la proposición vinculada a la Innovación (Ser una persona innovadora), que el resto de las instituciones de la Región. Véase la Tabla 3.

Tabla 3: Porcentaje de estudiantes por áreas de estudio y universidad, según tipo de concepto emprendedor, Coquimbo, Chile, 2015

\begin{tabular}{lllll}
\hline \multirow{2}{*}{ Variable } & \multicolumn{3}{c}{ Tipo de concepto emprendedor } \\
\cline { 3 - 5 } & Iniciar un negocio & Estilo de vida & Ser innovador \\
\cline { 2 - 5 } & Ingeniería & 27,1 & 24,0 & 49,0 \\
\cline { 2 - 5 } & Ciencias exactas y salud & 39,1 & 15,9 & 45,1 \\
\cline { 2 - 5 } & Ciencias sociales & 37,0 & 20,1 & 43,0 \\
\hline \multirow{2}{*}{ Universidad } & U. de La Serena & 39,1 & 26,0 & 34,9 \\
\cline { 2 - 5 } & U. Católica del Norte & 34,9 & 21,1 & 44,0 \\
\cline { 2 - 5 } & U. Santo Tomás & 27,1 & 14,8 & 58,1 \\
\cline { 2 - 5 } & U. Tecnológica de Chile Inacap & 44,0 & 13,0 & 43,0 \\
\cline { 2 - 5 } & U. Pedro de Valdivia & 18,5 & & 63,0 \\
\hline
\end{tabular}

Fuente: Elaboración propia, 2018

Finalmente, se observó que en las instituciones universitarias consultadas, los conceptos de emprendimiento e innovación se perciben por el alumnado y el profesorado como términos inherentes, por lo que no se concibe emprender sin innovar. Esta concepción se alinea con la idea de que las empresas que no dependen de su innovación para crecer, poseen pocas posibilidades de competir a gran escala y adaptarse de mejor manera a los cambios generados en la industria (Fuentelsaz y Montero, 2015).

\subsubsection{Satisfacción con las actividades y herramientas de emprendimiento enseñadas}

Casi la totalidad del alumnado (89\%) concuerda en afirmar que las herramientas y conocimientos entregados por sus docentes en clases contribuyen a emprender, por lo que se aprecia un bajo nivel de insatisfacción respecto de su enseñanza (11\%).

El estudiantado declaró que las actividades de emprendimiento que se desarrollan en sus carreras son: ferias de negocios (31\%), talleres (28\%), seminarios $(22 \%)$, congresos (16\%) y un pequeño porcentaje agregó que se realizaban otras alternativas (3\%), como las charlas. De ellas, manifestaron preferir para su formación emprendedora y en orden de importancia: ferias de negocios (27\%), seminarios (25\%), talleres $(25 \%)$ y congresos $(23 \%)$. 
Respecto del grado de satisfacción con los contenidos vistos en clases, se observó un alumnado mayormente satisfecho (66\% registró niveles entre alto o muy alto), seguido de estudiantes medianamente satisfechos (29\%) y una pequeña cuantía de jóvenes insatisfechos con lo aprendido (5\% registró niveles entre bajo o muy bajo). Véase la Tabla 4. Cabe señalar que no se hallaron asociaciones significativas entre el nivel de satisfacción del estudiantado con el área de desempeño de la profesión o con las universidades bajo estudio.

Tabla 4: Porcentaje de estudiantes por áreas de estudio según nivel de satisfacción, Coquimbo, Chile, 2015

\begin{tabular}{lccccc}
\hline Área / Nivel de Satisfacción & Muy alto & Alto & Regular & Bajo & Muy Bajo \\
\hline Ciencias Sociales & 21,6 & 59,3 & 14,0 & 4,3 & 0,9 \\
Tecnología & 41,0 & 40,0 & 13,5 & 5,5 & 0,0 \\
Arte y Diseño & 0,0 & 40,0 & 40,0 & 20,0 & 0,0 \\
Ciencias Exactas y Naturales & 21,0 & 36,0 & 43,0 & 0,0 & 0,0 \\
Salud & 0,0 & 70,0 & 30,0 & 0,0 & 0,0 \\
Agropecuaria & 17,0 & 50,0 & 33,0 & 0,0 & 0,0 \\
Promedio General & 16,8 & 49,2 & 28,9 & 5,0 & 0,2 \\
\hline
\end{tabular}

Fuente: Elaboración propia, 2018

Referente a los aspectos mencionados por el alumnado para potenciar la enseñanza recibida, destacan el deseo de que las asignaturas sean más prácticas, experimentales, en formato taller, con estudios de casos reales y que incluyan actividades que impliquen un rol activo del estudiantado (como las salidas a terreno y la interacción con emprendedores y emprendedoras). Esto permite apreciar el valor de las metodologías activas de enseñanzaaprendizaje, y en especial del aprendizaje experiencial, como una oportunidad para el desarrollo de competencias emprendedoras, una alternativa, cuyo enfoque de aprender haciendo, posibilitaría la construcción de aprendizajes significativos desde la autoexploración y experimentación (Marcillo, Veloz, Solís y Haro, 2019).

Por lo demás, se advierte la necesidad de articular diseños curriculares congruentes con un perfil basado en competencias emprendedoras. De este modo, las mejoras debiesen apuntar a una distribución adecuada de la carga horaria de las materias, la inclusión formal de métodos y actividades de aprendizaje efectivas orientadas al desarrollo de dichas competencias (Rodríguez y Gómez, 2014) y la implementación de sistemas de evaluación diferentes a los métodos tradicionales, que descuidan los procesos formativos dado su afán excesivo por la medición de los productos de aprendizaje (Moreno, 2012). 
Ello supone que cuando se aplica el emprendimiento a la educación formal, los currículos no deben limitarse solo a potenciar el conocimiento técnico en herramientas de emprendimiento, sino también a formar al estudiantado en actitudes y en saber efectivamente cómo manejar una empresa. Tal como concluyen Ahmad et al. (2018), debe existir un vínculo entre la teoría y la práctica para garantizar un aprendizaje efectivo, donde las personas educandas aprendan a ver el emprendimiento como un viaje en lugar de un destino, lo que incluye un recorrido personal tanto en lo cognitivo como en lo emocional y afectivo (Welsh, Tullar y Nemati, 2016). Esta visión fue, igualmente, compartida por el profesorado, quienes manifestaron relevante avanzar hacia una formación integral que incluya el desarrollo de habilidades, actitudes y valores. Como, por ejemplo, se revela en el relato de la ENTREVISTA9: "Hay que formar ciudadanos que sean responsables, lo fundamental es el respeto [...], no solamente esto tiene que ver con el crecimiento económico, sino, también con el tema de la sustentabilidad". O en la ENTREVISTA12: "Lo primero es la actitud, tener la capacidad de poder enfrentarte a una oportunidad de negocio no solamente desde el punto de vista comercial, sino que también humano, estar en condiciones de enfrentar fracasos".

A su vez, se develó la necesidad de recibir mayor apoyo y orientación del profesorado al momento de querer emprender, en especial fuera del aula de clases y del marco de las horas pedagógicas planificadas. Entre los contenidos tratados, existe inquietud por conocer los pasos esenciales para la constitución y puesta en marcha de un negocio, principalmente en sus aspectos jurídicos, tributarios y financieros, así como también de acceso a información sobre los concursos y programas existentes de apoyo al emprendimiento (financiamiento, capacitación y redes de colaboración). Estas debilidades abren oportunidades para la implementación de programas de mentoring (Guerra y Lobato, 2016) y uso de plataformas virtuales como herramientas complementarias de comunicación entre docentes y estudiantes (Peris-Ortiz, Gómez, Vélez-Torres y Rueda-Armengot, 2016).

Por otra parte, el alumnado mencionó otros aspectos a potenciar, tales como enseñar métodos para hablar eficazmente en público, que los proyectos realizados tengan un carácter más social (emprendimiento e innovación social) y que estos atiendan a problemáticas regionales o propias de la zona (Patiño, Cruz y Gómez, 2017). Referente a esto, el profesorado mostró coincidencia y agregó la importancia de formar líderes (ENTREVISTA5: "Buscar el desarrollo de habilidades [...] como habilidades de liderazgo, comunicacionales, de trabajo en equipo") capaces de atender proyectos que resuelvan 
problemáticas sociales reales, consideradas más complejas (ENTREVISTA 8: "este tipo de emprendimiento (social) es un poco más profundo que el emprendimiento tradicional [...] por lo que las personas necesitan estar mucho más preparadas para poder observar y juntar la información para después empezar a crear soluciones").

También, el estudiantado, considera conveniente compartir con jóvenes de otras universidades y de otros cursos de niveles más avanzados al momento de realizar los proyectos, con el fin de intercambiar información y experiencia (aprendizaje colaborativo). En relación con este último punto, Contreras-Velásquez, Wilches-Duran, Graterol-Rivas y Bautista-Sandoval (2017) confirmaron los beneficios del trabajo colaborativo interdisciplinar en equipos emprendedores y advirtieron la necesidad de diseñar cursos de formación en emprendimiento transversales, factibles de ser aplicados en cualquier programa académico. Tal como esgrimen Herrán y Pesántez (2016) las universidades innovadoras deben responder al desafío de socializar el conocimiento desde una estrategia global y compleja para vivir juntos.

Al respecto, resulta interesante la propuesta generada por la Comisión Europea en su Plan de Acción sobre Emprendimiento 2020, en la que se invita a que las instituciones de enseñanza superior ofrezcan una gama de cursos (optativos, extracurriculares, concursos, etc.), a no limitarse a un modelo particular de enseñanza y a ser más flexibles en el diseño de las materias, ofertar, por ejemplo, estudios durante tiempo completo y parcial, organizar cursos intensivos, proponer periodos de prácticas y acreditar aprendizajes tanto formales como no formales. Todo ello con el objeto de instaurar un ambiente dinámico y activo que garantice que sus participantes desarrollen y vivan una cultura del emprendimiento y la innovación a través de sus planes de estudio y resultados del aprendizaje (Arruti, 2015) .

\section{Conclusiones}

Del análisis de los resultados, se concluye que el profesorado que enseña emprendimiento en Chile (Región de Coquimbo) posee un perfil demográfico y profesional homogéneo. En general, son personas jóvenes (36 años) que tienen una experiencia académica promedio de once años y se dedican a enseñar emprendimiento por cerca de seis años. La mayoría (60\%) cuenta con formación profesional básica en el área de la administración y negocios (principalmente de las carreras de ingeniería comercial e ingeniería industrial) y, aun cuando casi la totalidad presenta formación de posgrado, solo la mitad posee alguna especialización concreta en el área de emprendimiento e innovación. Lo 
anterior es llamativo si se considera que diversos estudios postulan que la formación de personas emprendedoras requiere de un profesorado especializado, que cuente con ciertas características y competencias fundamentales para el desarrollo efectivo del proceso de enseñanza-aprendizaje, y que puedan certificarse mediante una formación particular en el área (Arruti, 2015; Barnett, Byrd y Wieder, 2013; Pertuz-Peralta, Rojas-Caicedo, NavarroRodríguez y Quintero, 2016).

Al respecto, Sánchez et al. (2017) señalan que uno de los retos más relevantes que enfrenta el sistema educativo actual es promover la formación del profesorado en metodologías y técnicas efectivas que permitan desarrollar la innovación y el emprendimiento en los procesos de enseñanza y aprendizaje. Así, los métodos tradicionales deben evolucionar hacia nuevos modelos centrados en el aprendizaje experiencial y vivencial en contextos de interdisciplinariedad (Contreras-Velásquez et al., 2017) que potencien el desarrollo de actitudes y competencias emprendedoras.

También, los resultados destacan la experiencia empresarial del profesorado (el $85 \%$ tiene o tuvo empresas), cuyos emprendimientos se han desarrollado, fundamentalmente, en el área de la consultoría y las capacitaciones. Este punto cumple las expectativas tanto de docentes como de estudiantes, quienes reconocen como requisito importante para enseñar a emprender haber emprendido con anterioridad, lo que consideran como un aporte adicional y enriquecedor al proceso de enseñanza-aprendizaje.

Lo anterior evidencia la preponderancia de contar con docentes preparados no solo en el ámbito técnico para la enseñanza del emprendimiento (creación y gestión de empresas), sino que cuenten con las competencias emprendedoras que buscan formar en su alumnado. De manera tal que sean percibidos como modelos o referentes en la materia. Tal como indican Castro et al (2014) no puede procurarse formar un alumnado emprendedor si no se cuenta con un profesorado idóneo, que se vea motivado por emprender, además de involucrado por desarrollar una nueva pedagogía (Núñez y Núñez, 2018) orientada en instruir sujetos con capacidad para tomar decisiones cimentadas en el sentido crítico y la responsabilidad.

En relación con la noción de emprender, se demuestra que el perfil psicológico asociado al término emprendedor es la preferencia por la innovación (Marulanda, Correa y Mejía, 2009), más allá de otras acepciones como aquella tradicionalmente vinculada al deseo de lograr la independencia (iniciar un negocio propio). Dicha visión, posibilita trabajar el emprendimiento desde una perspectiva más holística, que incluye la concepción de 
emprender para innovar dentro de las mismas organizaciones en que los trabajadores y trabajadoras se desempeñan (intraemprendimiento).

Se determinó, además, que existe una alta valorización y satisfacción del alumnado respecto a los conocimientos, contenidos y herramientas transferidas en las asignaturas de emprendimiento cursadas, especialmente con: Business Model Canvas, Plan de Negocios y Método Lean Start-up. Las actividades de emprendimiento preferidas por el estudiantado son las ferias de negocios, los talleres, los seminarios y los congresos. Sin embargo, también se evidencia el deseo de potenciar los programas de estudios con la inclusión de más actividades prácticas y multidisciplinarias, con un rol docente más activo y que involucre también tópicos vinculados al emprendimiento e innovación social. Punto relevante si se considera que el diseño curricular se identifica como un factor clave de la calidad educativa (Casanova, 2012).

En último lugar, se recomienda en futuras investigaciones extender el área de estudio a otras instituciones de educación superior (institutos profesionales y centros de formación técnica) e incorporar la opinión de más agentes claves del ecosistema de emprendimiento regional (instituciones públicas, incubadoras, personas que hayan emprendido y organismos de apoyo al emprendimiento), lo que permitiría obtener un panorama más amplio sobre la evolución de la educación emprendedora y los desafíos que enfrenta su enseñanza.

Como reflexión final, cabe denotar que si se desea implementar una educación universitaria efectiva para el emprendimiento, esta debe planificarse desde una visión global, declarada y garantizada institucionalmente, que esté presente en los planes estratégicos, planes operativos, programas de estudios, programaciones anuales y planificaciones de clases. De este modo, al integrar el emprendimiento en todas las fases del sistema educativo, se asegura el ofrecimiento de un proyecto educativo sostenible, coherente, basado en la consolidación de las competencias emprendedoras.

\section{Agradecimientos}

A los ingenieros comerciales de la Universidad de La Serena: Diego Rojas Santander y Wilson Pizarro Trigo, por sus aportes en la gestión de la base de datos empleada y en la obtención de algunos resultados preliminares. 


\section{Referencias}

Ahmad, Noor; Halim, Hasliza; Ramayah, Thurasamy; Popa, Simona y Papa, Armando. (2018). The ecosystem of entrepreneurial university: the case of higher education in a developing country. International Journal of Technology Management, 78(1/2), 52. Doi: https://doi.org/10.1504/ijtm.2018.093935

Ahmad, Syed; Abu Bakar, Abdul y Ahmad, Norita. (2018). An evaluation of teaching methods of entrepreneurship in hospitality and tourism programs. International Journal of Management Education, 16(1), 14-25. Doi: https://doi.org/10.1016/j.jjme.2017.11.002

Aldana-Rivera, Edna; Tafur-Castillo, Janery; Gil, Ivon y Mejía, César. (2019). Práctica pedagógica de emprendimiento en docentes de educación superior en Institución Educativa Universitaria de Barranquilla. Revista AVFT, 38(2), 9-18. Recuperado de http://www.revistaavft.com/images/revistas/2019/avft_2_2019/2practica_pedagogica_em prendimiento.pdf

Alvarez, Ricardo; DeNoble, Alex y Jung, Don. (2006). Educational Curricula and Self-Efficacy: Entrepreneurial Orientation and New Venture Intentions among University Students in Mexico. International Research in the Business Disciplines, 5, 379-403. Doi: https://doi.org/10.1016/S1074-7877(06)05019-7

Arruti, Arantza. (2015). El desarrollo del perfil del "teacherpreneur" o profesor-emprendedor en el currículum del grado de Educación Primaria: ¿un concepto de moda o una realidad? Contextos Educativos. Revista de Educación, 19(2016), 177-194. Doi: https://doi.org/10.18172/con.2770

Barba-Sanchez, Virginia y Atienza-Sahuquillo, Carlos. (2017). Entrepreneurial intention among engineering students: The role of entrepreneurship education. European Research on Management and Busines Economics, 24(2018), 53-61. Doi: https://doi.org/10.1108/S2040-724620170000007009

Barnett, Berry; Byrd, Anne y Wieder, Alan. (2013). Teacherpreneurs: Innovative Teachers Who Lead But Don 't Leave. San Francisco: Jossey-Bass.

Čapienè, Aistè y Ragauskaitè, Aistè. (2017). Entrepreneurship Education at University: Innovative Models and Current Trends. Research for Rural Development, 2, 284-291. Doi: https://doi.org/10.22616/rrd.23.2017.080

Casanova, María Antonia. (2012). El diseño curricular como factor de calidad educativa. Revista Iberoamericana Sobre Calidad, Eficacia y Cambio En Educación, 10(4), 20. Doi: https://doi.org/10.14718/RevArq.2013.15.1.9

Castillo, Alicia. (1999). Estado del Arte en la Enseñanza del Emprendimiento. Emprendedores Como Creadores de Riqueza y Desarrollo Regional. Santiago: INTECCHILE.

Castro, Ana; Renés, Paula y León, Beatriz. (2014). La educación para el emprendimiento: el caso de Cantabria. Procedia - Social and Behavioral Sciences, 139(2014), 512-518. Doi: https//doi.org/10.1016/j.sbspro.2014.08.056 
Catalán, Arturo. (2016, June 20). Emprendimiento e innovación ya son ramos obligatorios en más de 100 programas de estudios. El Mercurio. Recuperado de http://www.economiaynegocios.cl/noticias/noticias.asp?id=263898

Chapa, E. A. (2008). Programa Emprendedor Obligatorio. Alternativa de Educación Integral. Formación Universitaria, 1(6), 353-357. Doi: https://doi.org/10.4067/S071850062008000600006

Comisión Europea. (2013). Plan de acción sobre emprendimiento 2020. Relanzar el espíritu emprendedor en Europa. Bruselas: Comisión Europea. Recuperado de http://ec.europa.eu/transparency/regdoc/rep/1/2012/ES/1-2012-795-ES-F1-1.Pdf.

Contreras-Velásquez, Julio; Wilches-Duran, Sandra; Graterol-Rivas, Modesto y BautistaSandoval, María. (2017). Educación Superior y la Formación en Emprendimiento Interdisciplinario: Un Caso de Estudio. Formación Universitaria, 10(3), 11-20. Doi: https://doi.org/10.4067/S0718-50062017000300003

Díaz-García, Cristina; Sáez-Martínez, Francisco y Jiménez-Moreno, Juan. (2015). Evaluación del impacto del programa educativo "Emprendedores " en la intención emprendedora de los participantes. RUSC. Universities and Knowledge Society Journal, 12(3), 17-31. Doi: http://dx.doi.org /10.7238/rusc.v12i3.2146

Doğan, Ebru. (2015). The Effect of Entrepreneurship Education on Entrepreneurial Intentions of University Students in Turkey. The Journal of Entrepreneurship, 23(1), 1-18. Doi: https://doi.org/10.1177/0971355713513346

Fuentelsaz, Lucio y Montero, Javier. (2015). ¿Qué hace que algunos emprendedores sean más innovadores? Universia Business Review, 2015(47), 14-31. Recuperado de http://www.redalyc.org/articulo.oa?id=43341001001

Gibb, Allan. (2002). In Pursuit of a New "Enterprise" and "Entrepreneurship" Paradigm for Learning: Creative Destruction, New Values, New Ways of Doing Things and New Combinations of Knowledge. International Journal of Management Reviews, 4(3), 233$269 . \quad$ Recuperado de http://citeseerx.ist.psu.edu/viewdoc/download?doi=10.1.1.465.9414\&rep=rep1\&type=pdf

González-García, Guadalupe; Becerril, María Luisa y Fonseca, Adriana. (2018). El engagement como factor de formación y desarrollo de la cultura emprendedora en estudiantes universitarios. IE Revista de Investigación Educativa de La REDIECH, 9(17), 103. Doi: https://doi.org/10.33010/ie_rie_rediech.v9i17.120

Guerra, Nagore y Lobato, Clemente. (2016). Características del mentoring en un Programa de innovación educativa con profesorado universitario. International Journal of Developmental and Educational Psychology, 1(1), 521-530. Doi: https://doi.org/10.17060/ijodaep.2015.n1.v1.83

Gutiérrez, Jahir; Asprilla, Elimeleth y Gutiérrez, José. (2016). Estado del Arte del Emprendimiento Empresarial en Materia de Ciencia, Tecnología e Innovación. Revista Universitaria Ruta, 18(2), 1-25. Doi: https://doi.org/10.15433/ruta.v18i2.795 
Hattab, Hala. (2014). Impact of Entrepreneurship Education on Entrepreneurial Intentions of University Students in Egypt. The Journal of Entrepreneurship Education, 23(1), 1-18. Doi: $10.1177 / 0971355713513346$

Herrán, Javier y Pesántez, Lauro. (2016). La universidad innovadora. Revista Cubana de Educación Superior, 47-63. Recuperado de http://scielo.sld.cu/pdf/rces/v35n3/rces04316.pdf

Herrera, Raúl y Villalobos, Marco. (2018). Caracterización de la Formación Académica en Emprendimiento de Pregrado que se realiza en Universidades Chilenas. Formación Universitaria, 11(4), 43-52. Doi: https://doi.org/10.4067/S0718-50062018000400043

Ismail, Annafatmawaty; Sawang, Sukanlaya y Zolin, Roxanne. (2018). Entrepreneurship Education Pedagogy: Teacher-Student-Centred Paradox. Education \& Training, 60(2), 168-184. Doi: https://doi.org/10.1108/ET-07-2017-0106

Jaramillo, Leonor. (2008). Emprendimiento: Concepto básico en competencias. LumenInstituto de Estudios en Educación, 7, 1-6. Recuperado de http://guayacan.uninorte.edu.co/divisiones/iese/lumen/ediciones/7/articulos/emprendimie nto.pdf

Karim, Mohd. (2016). Entrepreneurship Education in an Engineering Curriculum. Procedia Economics and Finance, 35 (October 2015), 379-387. Doi: https://doi.org/10.1016/S2212-5671(16)00047-2

Kirby, David. (2004). Entrepreneurship education: can business schools meet the challenge ? Education + Training, 46(8/9), 510-519. Doi: https://doi.org/10.1108/00400910410569632

Londoño, José. (2018). Educación para emprender ¿práctica o teoría?. Revista Argentina de Investigación en Negocios, 4(1), 97-106. Recuperado de http://ppct.caicyt.gov.ar/index.php/rain/article/download/V4n1a8/pdf

Luis, María Isabel; Palmero, Carmen y Escolar, María Camino. (2015). Impacto de la educación en el emprendimiento. Making-of y análisis de tres grupos de discusión. Pedagogía Social. Revista Interuniversitaria, (25), 221-250. Doi: https://doi.org/10.7179/PSRI_2015.25.10

Mahendra, Angga; Djatmika, Ery y Hermawan, Agus. (2017). The Effect of Entrepreneurship Education on Entrepreneurial Intention Mediated by Motivation and Attitude among Management Students, State University of Malang, Indonesia. International Education Studies, 10(9), 61. Doi: https://doi.org/10.5539/ies.v10n9p61

Mandakovic, Vesna y Serey, Tomás. (2017). Global Entrepreneurship Monitor. Reporte Nacional de Chile 2017.2 Recuperado de https://home.asech.cl/uploads/library/5b1027f84cf8c_GEM FINAL.pdf

Marcillo, Marcillo; Veloz, Elena; Solís, Marlene y Haro, Abel. (2019). Aprendizaje experiencial y su aplicación en el proceso de enseñanza y aprendizaje (1st ed.). Recuperado de http://142.93.18.15:8080/jspui/bitstream/123456789/312/1/Aprendizaje Experiencial y su Aplicaciòn en el Proceso de Ensenanza y Aprendizaje.pdf 
Maresch, Daniela; Harms, Rainer; Kailer, Norbert y Wimmer-Wurm, Birgit. (2016). The impact of entrepreneurship education on the entrepreneurial intention of students in science and engineering versus business studies university programs. Technological Forecasting and Social Change, 104, 172-179. Doi: https://doi.org/10.1016/j.techfore.2015.11.006

Marulanda, Andrés; Correa, Geovanny y Mejía, Luis. (2009). Emprendimiento: Visiones desde las teorias del comportamiento humano. Revista Escuela de Administración de Negocios, (66), 153-168. Recuperado de https://www.redalyc.org/pdf/206/20620269008.pdf

Marulanda, Flor; Montoya, Iván y Vélez, Juan. (2014). Aportes teóricos y empíricos al estudio del emprendedor Resumen. Cuadernos de Administración, 30(51), 89-99. Recuperado de http://www.scielo.org.co/pdf/cuadm/v30n51/v30n51a10.pdf

Ministerio de Economía, Fomento y Turismo. (2015). Informe $N^{\circ}$ 3: Pilotos para la incorporación de habilidades de innovación y emprendimiento en el sistema escolar. Recuperado de https://www.economia.gob.cl/wpcontent/uploads/2015/07/Emprendimiento-escolar.pdf

Moreno, Tiburcio. (2012). La evaluación de competencias en educación. Sinéctica, 39. Recuperado de http://www.scielo.org.mx/pdf/sine/n39/n39a10.pdf

Núñez, Luis y Núñez, Margarita. (2018). Papel del profesor motivado en la educación emprendedora en España. Revista Empresa y Humanismo, 21(1), 7-40. Doi: https://doi.org/10.15581/015.XXI.1.7-40

Paños, Jessica. (2017). Educación emprendedora y metodologías activas para su fomento. Revista Electrónica Interuniversitaria de Formación Del Profesorado, 20(3), 33. Doi: https://doi.org/10.6018/reifop.20.3.272221

Patiño, Omar; Cruz, Edwin y Gómez, Martha (2017). Estudio de las competencias de los emprendedores/innovadores sociales. El caso del Premio ELI de la Universidad EAN. Revista EAN, (81), 75. Doi: https://doi.org/10.21158/01208160.n81.2016.1557

Peris-Ortiz, Marta; Gómez, Jaime; Vélez-Torres, Francisco y Rueda-Armengot, Carlos. (2016). Education Tools for Entrepreneurship: Creating an Action-Learning Environment through Educational Learning Tools. In Springer. Doi: https://doi.org/10.1007/978-3-31924657-4_5

Pertuz-Peralta, Vanessa; Rojas-Caicedo, Gloria; Navarro-Rodríguez, Astrid y Quintero, Liliana. (2016). Perfil docente y fomento de la cultura del emprendimiento: búsqueda de una relación. Educación y Educadores, 19(1), 29-45. Doi: https://doi.org/10.5294/edu.2016.19.1.2

Poblete, Carlos y Amorós, José (2013). University Support in the Development of Regional Entrepreneurial Activity: An Exploratory Study from Chile. Investigaciones Regionales, 26(2013), 159-177. Recuperado de http://www.redalyc.org/articulo.oa?id=28928246008

Prasetio, Eko. (2016). Assessing the impact of entrepreneurship education on entrepreneurial self- efficacy (ESE) and entrepreneurial intention (EI): a longitudinal study. Doi: https://doi.org/10.13140/RG.2.1.1969.9607 
Rodríguez, Alfonso. (2009). Nuevas perspectivas para entender el emprendimiento empresarial. Pensamiento \& Gestión, (26), 94-119. Recuperado de http://www.redalyc.org/articulo.oa?id=43341001001

Rodríguez, Diana y Gómez, Adriana. (2014). Las competencias emprendedoras en el departamento de Boyacá. Apuntes Del CENES, 33(58), 217-242. Recuperado de http://0-search.proquest.com.diana.uca.es/docview/1654559740?pq-

origsite=summon\#center

Samwel, Ernest. (2010). Entrepreneurship education: A review of its objectives, teaching methods, and impact indicators. Education and Training, 52(1), 20-47. Doi: https://doi.org/10.1108/00400911011017663

Sánchez, José; Ward, Alexander; Hernández, Brizeida y Florez, Jenny. (2017). Educación emprendedora: Estado del arte. Propósitos y Representaciones, 5(2), 401-473. Doi: https://doi.org/10.20511/pyr2017.v5n2.190

Sogunro, Olusegun. (2004). Efficacy of role-playing pedagogy in training leaders: some reflections. Journal of Management Development, 23(4), 355-371. Doi: https://doi.org/10.1108/02621710410529802

Sondari, Mery. (2014). Is Entrepreneurship Education Really Needed?: Examining the Antecedent of Entrepreneurial Career Intention. Procedia - Social and Behavioral Sciences, 115(2014), 44-53. Doi: https://doi.org/10.1016/j.sbspro.2014.02.414

Soria-Barreto, Karla; Zuniga-Jara, Sergio y Ruiz-Campo, Sofía. (2016). Educación e intención emprendedora en estudiantes universitarios: Un caso de estudio. Formacion Universitaria, 9(1), 25-34. Doi: https://doi.org/10.4067/S0718-50062016000100004

Soria-Barreto, Karla; Zúñiga-Jara, Sergio y Ruiz, Sofía. (2016). Determinantes de la intención emprendedora: Nueva Evidencia. Interciencia, 41(5), 325-330. Recuperado de http://www.redalyc.org/articulo.oa?id=33945552006

Soria, Karla y Honores, Guillermo. (2016). GEM, Informe de la Región de Coquimbo 2014 , Chile. Santiago: Andros Impresores.

Stamboulis, Yeoryios y Barlas, Achilleas. (2014). Entrepreneurship education impact on student attitudes. International Journal of Management Education, 12(3), 365-373. Doi: https://doi.org/10.1016/j.jme.2014.07.001

Vásquez, César. (2017). Educación para el emprendimiento en la universidad. Estudios de la Gestión: revista internacional de administración, (2), 121-147. Recuperado de http://repositorio.uasb.edu.ec/bitstream/10644/5957/1/07-ES-Vasquez.pdf

Welsh, Dianne; Tullar, William y Nemati, Hamid. (2016). Entrepreneurship education: Process, method, or both? Journal of Innovation \& Knowledge, 1(3), 125-132. Doi: https://doi.org/10.1016/j.jik.2016.01.005 
Revista indizada en
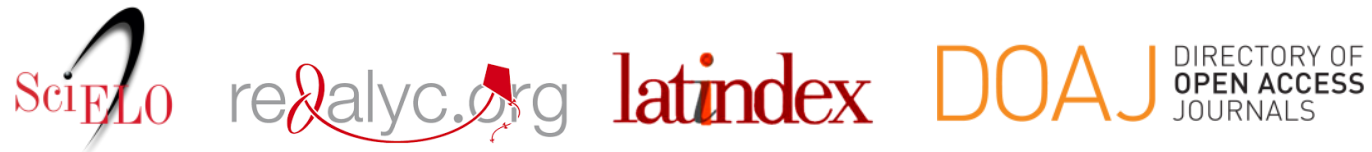

Distribuida en las bases de datos:

๑ Dialnet

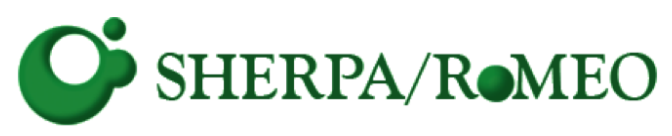

REDIB

Red Iberoamericana

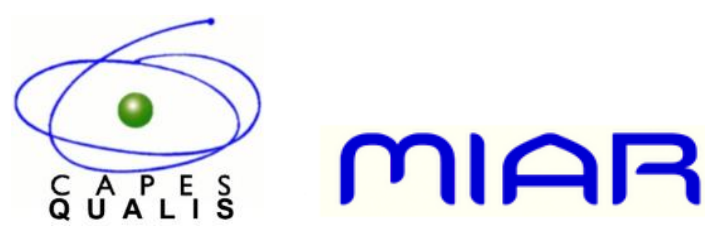

